\title{
Practice and Exploration on Opto-Electronic Engineering Personnel Training Mode in Application-oriented Colleges
}

\author{
Junjie Wang ${ }^{1, a}$ and Dong Xue ${ }^{1,2, b *}$ \\ ${ }^{1}$ School of Opto-Electronic Engineering, Zaozhuang University, Zaozhuang 277160, China \\ ${ }^{2}$ Zaozhuang Engineering Research Center of Terahertz, Zaozhuang 277160, China \\ a458692589@qq.com, ${ }^{\text {b }}$ fiberlaser@126.com \\ * the corresponding author
}

Keywords: Personnel training mode; Application-oriented colleges; Opto-electronic engineering

\begin{abstract}
At the present, with the development of education in China shifted from scale development to connotation development, the personnel training mode of applied talents has become a problem that needs to be addressed emphatically. This paper study and explore the ideological and practical mode of self-development of local application-oriented colleges, based on the talent cultivation practice of Zaozhuang University.
\end{abstract}

Acknowledgement: This work is supported by the program of independent innovation and achievement transformation plan for Zaozhuang (2016GH19); Science and technology program of Zaozhuang 2016GX31).

\section{应用型大学光电工程人才培养实践和探索 王俊杰 ${ }^{1, \mathrm{a}}$, 薛冬 ${ }^{1,2, \mathrm{~b},{ }^{*}}$ \\ 1 本庄学院光电工程学院, 本庄, 山东, 中国 2 本庄市太赫兹工程技术研究中心, 本庄, 山东, 中国}

摘要: 在我国高等教育由规模发展转向内涵发展的现阶段, 应用型人才培养已成为需要着重解决的问题。本文以本庄学 院光电工程学院人才培养实践为例研究和探索地方高校自我发展的办学思想和实践模式, 探索应用型大学建设的有效途径。

关键词: 人才培养模式; 应用型大学; 光电工程

中图分类号: G642.0 文献标志码:

\section{引言}

在我国高等教育由规模发展转向内涵发展的现阶段, 应用型人才培养已成为需要着重解决的问题 [1-3]。光电工程学院坚持以中国特色的社会主义理论为指导, 坚持学院的 “求知重能, 求新重实, 求精 重质” 的办学理念, 重视学生能力的培养, 重视实践教学、紧密联系实际、开展应用研究。我院以 “光学 工程” 省级重点建设学科、“应用电子” 省级特色专业及 “电子信息工程”、“光电信息科学与工程” 等 优势专业的建设为基础, 以光电信息技术类创新型人才培养为主要目标, 借鉴外校先进经验 $[4,5]$, 在多 年的人才培养过程中，形成了具有鲜明特色的人才培养模式。

\section{1 教师队伍建设}

光电工程学院拥有教职工 46 人，其中专任教师 39 人，教授 6 人，副教授 7 人，硕士以上研究生 36 人，博 士9人, 专职教师中具有硕士学位以上学历的教师占教师总数的 $92 \%$ 。拥有长江学者 1 人, 山东省教学名师 
1 人，获国家自然科学基金资助 5 人，山东省中青年科学家基金资助 3 人。近年来，我院十分注重师资队伍 的建设和发展, 注意加强教师职业道德和敬业精神的培养, 加强教师业务学习和教学研究活动, 不断更新 知识、改善教师的知识和技能结构, 提高教师的自身素质, 以适应教学改革的需要。教师在教学过程中进 行规范化教学, 精选教学内容, 改进教学方法和手段, 严谨治学。重视青年教师的培养, 严格执行青年教 师导师制的培养计划, 为青年教师配备专门的指导老师, 负责指导青年教师的讲稿撰写、备课试讲、教学 研究和课程教授等, 加快青年教师的成长步伐。年轻队伍已成为光电工程学院师资队伍的骨干力量, 师资 队伍整体水平不断提高。长期以来, 团队成员团结一致, 严谨治学, 教书育人, 积极进取, 多次受到表彰。

教学团队还聘请特聘教授 8 人, 分别来自中国科学院、天津大学、南开大学等国内知名院所, 其中著 名的光电子学专家姚建铨院士受聘我校。兼职教授具有深厚的学术造诣和创新性学术思想, 在指导教学团 队进行创新教育、科学研究、师资队伍建设等方面起到了推动作用。

\section{2 打造服务地方经济的专业发展框架}

光电工程学院前身是東庄学院物理与电子工程系, 始建于1978年, 是我校最早建设的系科之一。经过 历届领导与全系师生的共同努力, 2005年为适应学校由师范院校到综合性院校转变的需要, 申报物理学和 电子信息工程两个本科专业, 并分别于 2005年和2006年获得教育部批准开始招生, 至今已有 4 届毕业生, 2012年开设了光电信息工程专业, 主要方向为光伏太阳能领域。光电工程学院现已发展成为拥有光电信息 工程、电子信息工程本科专业为主体的, 以应用电子技术专科专业为辅助的光电信息技术类人才培养体系。

这些专业的开设立足于東庄市及其周边地区经济发展的需要, 毕业生面向光伏及电子行业, 经过几年 的发展, 逐步确立了以社会需求和就业为导向、 “服务地方, 特色发展” 办学理念, 以人为本的服务理念, 以能力培养为主线的教学理念, 以教育教学为中心的管理理念和可持续发展的建设理念。

\section{3 探索服务地方经济的人才培养模式}

为了指导和促进光电信息技术类人才的培养, 根据束庄学院始终坚持 “服务地方, 特色发展” 的发展 战略, 为柊庄及其周边区域经济社会发展培养急需人才。根据《冭庄学院 “十二五” 学科建设与发展规划》, 本光电工程学院明确了人才培养目标、培养模式、培养重点和具体措施。

针对光伏、电子产业对人才的需求, 主动适应区域经济发展和科技进步的需要, 以突出行业技术所必 需的知识能力, 面向产业和行业培养 “厚基础、宽口径、懂技术、高素质、有特色” 的创新型专业技术人 才。

为贯彻《教育部等部门关于进一步加强高校实践育人工作的若干意见》、《㫫庄学院教学计划修订指 导意见》文件精神, 强化实践教学环节, 提高实习、实践学分比例, 突出学生实践能力培养, 积极推行小 学期开展实习实践课程的教学模式, 先后修订了《电子信息工程应用型人才培养方案》、《光电信息工程 应用型人才培养方案》、《物理学应用型人才培养方案》、《应用电子技术应用型人才培养方案》等各类 应用型人才培养方案, 进一步明确了光电信息技术类专业人才培养的具体思路。

其中, 实践教学小学期制是利用小学期开展大学生的实践教学活动教学模式, 是我校光电工程学院一 项重要的教育教学改革, 较好地解决了传统 “二学期制” 难以实现优质教育资源共享和综合实践不足的问 题。2012年, 在学院党委的正确领导与支持下, 以教务处为龙头, 积极试行实践教学小学期制。为此, 我 
光电工程学院首派电子信息工程和应用电子技术专业150名大一学生, 赴企业进行为期两月的专业实习。 使同学们在一年级就对专业技能和行业要求有所了解, 遵照理论学习与实践训练相结合、校内实验与校外 实习相结合、小学期和暑假相结合、专业知识和行业技能相结合的原则, 突破了时间、空间和资源对实践 教学的局限, 为全校小学期实践教学的推广提供了有益尝试。

\section{4 服务地方经济的教学设施建设}

实验室建设: 经过多年努力, 光电工程学院现拥有实验室总面积 $4900 \mathrm{~m} 2$, 资产总值 1300 多万元。拥有 力学、热学、电磁学、光学、近代物理、应用电子技术、电力与电气、PLC、EDA、DSP、多功能家电、传 感器等教学实验室, 并拥有光电功能材料、光纤激光、太阳能光伏、电动汽车研发等专业实验室。2010年 我校与束庄市政府联合成立了苯庄市太阳能新技术应用工程技术研究中心。这些实验室（研究中心）的建 成极大地改善了我校教学科研条件。总之, 光电工程学院具备集教学、科研、服务于一体的多功能实验基 地, 为更好地对光电信息技术类人才的培养提供了良好的物质基础。

实践基地建设：近年来，光电工程学院与富士康科技工业园（烟台）、山东布特新能源科技有限公司 （青州）、山东科晶玻璃有限公司（市中）、山东奚仲电子科技有限公司（薛城）、山东海宏电子科技有 限公司（高新区）、杳庄金诺电控工程有限公司（市中）、杳庄伟华薄膜电路有限公司（市中）、山东同 济机电有限公司 (薛城) 、山东鲁南瑞虹化工仪器有限公司 (滕州) 等多家企业签署了技术服务与研究开 发、教师科研、教学实践基地等多项合作协议, 得到企业研发经费 80 万元。把企业的资金优势和我校人才 智力支持相结合, 建设了 8 个校企联合创新实验室: 光伏组件测试中心实验室、电光源测试中心实验室、 城市亮化中心实验室、光学薄膜中心实验室、以及电池技术中心实验室。我院研发的 “纳米低压钠灯” 产 品, 已顺利投产，年产值7000万元。我院研发的 “复合纳米薄膜制备仪”、“纳米防尘薄膜” 等设备已通 过中试, 即将实现产业化。上述实验基地每年可以接受总计 2000 人次的教学实践活动。我院与上述合作单 位签定人才培养合作协议, 设立人才培养专业实践基地, 加强对学生应用能力的培养, 毕业后深受企事业 单位的好评。

图书资料建设：光电工程学院现有相关专业图书资料共 6746册（包括电子图书），专业类期刊23种。 结合学校图书馆, 图书 86.5 万册, 现刊 1995 种, 数据库及电子出版物达 11500 件, 完全能够满足光电工程 学院人才培养的需要。

网络环境建设: 建立了《光学》、《电工学》、《电磁场与电磁波》、《大学物理》、《单片机》、 《信号与系统》多门校级优质课程, 其中《光学》课程 2008 年被评为省级精品课程, 《大学物理》和《电 工学》被评为 2012 年省级精品课程。

\section{5 积极开展教研活动和教改项目}

近几年来，光电工程学院发表教学教改论文 80 余篇; 承担了各类教改项目 20 余项: 《机电、电子信息 类专业实践教学模式研究》（山东省高等学校教学改革立项项目）、《教育信息化环境下教学过程出现的 问题与对策研究》（院级课题）、《基础物理实验教学信息化建设与教学改革研究》（院级课题）、《大 学物理实验教学改革和优秀实验中心建设的研究与实践》（院级课题）、《面向区域经济校企合作的光电 信息技术类人才培养模式创新实验区》 (院级课题) 等。出版教材、论著共 10 余本。拥有 “大学物理教学 
团队”、“光学教学团队” 两个院级教学团队, 其中 “光学教学团队” 又荣获2011年省级教学团队。“应 用电子技术” 2008年被评为校级特色专业, 2009年被评为省级特色专业。“光电工程” 被评为菄庄学院重 点建设学科, 2011年被评为山东省 “十二五” 重点学科。

我院近几年在专业学术期刊发表论文150多篇, 其中被SCI、EI、中文核心期刊收录80余篇。获得国家 973 项目子课题 2 项, 国家自然科学基金4项, 国家科技支撑计划子课题 2 项, 山东省发改委课题2项, 山东 省科技攻关项目 4 项, 市级科研立项课题 39 项; 其中, 与山东布莱特辉煌新能源有限公司共建的束庄市太 阳能新技术应用工程技术研究中心创造效益6000千多万元, 纳米低压钠灯已通过山东省科技厅鉴定, 其成 果已达到国内领先水平; 与束庄市安监局联合的安监项目创造效益 1000 千多万元; 编写教材 8 部; 获得省 级三等奖 3 项; 市级二等奖 9 项; 三等奖1项, 院级科研奖多项。

\section{6 广泛搭建实践平台, 拓展创新能力}

本光电工程学院十分注重学生基础理论知识和实验技能的培养, 注意学生的政治思想素质的提高, 形 成了优良的学风, 学生专业知识扎实, 英语和计算机水平较高, 积极参与科研活动, 社会创业实践活动, 在专业实践和各类教学、科技竞赛等活动中取得了令人满意的成绩。

2006年光电工程学院成立了科技创新兴趣型的学生创新团队---科技创新协会, 协会致力于培养同学 们对科学技术研究和科技创新的兴趣, 引导同学们提高自身的创新能力和协作精神, 以专业知识为基础, 锻炼提高动手能力和实践能力, 2012 年该协会获得 “山东省优秀大学生科技社团” 光荣称号。2009年光电 工程学院创立了创新实验室, 有专职教师辅导, 给同学们提供了创新创业的平台, 其作品在全国机电产品 设计大赛、电子竞赛、物理科技创新等比赛中屡屡获得佳绩, 获得了老师和同学们的一致好评, 为营造学 院良好的学术氛围做出了贡献; 同时我院的家电维修协会多次深入居民社区, 无偿维修家用电器, 不但切 实提高了学生的动手能力, 也获得社会各界的一致好评。

2009年起, 光电工程学院全面推行导师制培养模式, 制定了《光电工程学院本科生导师制工作条例》。 导师制的实施除了使教学上获得了明显的成效外, 并积极指导学生开展校级大学生科研训练 (SRT) 计划 项目。在导师的指导下, 完成从项目设计、实验、采集数据、分析结果、撰写论文、发表论文等一系列环 节, 提高了创新意识和科研能力。近3年（2014-2016）学生参与发表的论文20余篇, 部分论文被SCI、EI、 中文核心期刊收录。

光电工程学院鼓励学生积极参与各类科技创新比赛, 2016年在全国大学生英语竞赛、中国机器人大赛、 山东省大学生物理创新技能大赛、山东省大学生电子设计竞赛、山东省大学生机电产品创新设计竞赛中, 获一等奖 10 余项。

\section{7 结语}

综上所述, 我们已经在师资队伍建设、专业学科建设、人才培养、教学科研、实践平台建设等方面作 出了有益探索，为建设好 “地方性、有特色、应用型” 高校奠定了坚实的基础。

\section{致谢}

本文得到以下项目资助: 東庄市重点研发及科技成果转化项目（2016GH19），東庄市科技计划项目 (2016GX31)。 


\section{参考文献:}

[1] 张海军, 张淑兰, 戚晓利, 等. 地方高校创新创业人才培养模式改革探索与实践 $[J]$. 实验室研究与探索, 2017, 36 (8): $222-225$.

[2] 田海, 崔桂梅, 刘慧博, 等. 优秀创新人才培养模式的研究与实践 $[J]$. 实验室研究与探索, 2017，36 (8) :230-233.

[3] 张礼, 左玉生, 陈杰, 等. 独立学院大学物理实验预习系统开发与研究 [J]. 实验室研究与探索, 2017, 36 (7) : 203-206.

[4] 严文娟,贺国权. 技术应用型创新人才培养模式的探索与实践 [J]. 实验室研究与探索, 2016, 33 (6) : 203-206. 21-24.

[5] 张凌云, 董强, 肖新国. 应用型人才培养的产学研协同模式探索与实践-以合肥学院为例 $[J]$. 合肥学院学报 (自然科学 版), 2014, 24(4):70-73.

\section{References}

[1] Zhang Hai-jun, Zhang Shu-lan and Qi-Xiao-li, et al: "Exploration and Practice of Personnel Training Mode on Innovation Entrepreneurship Education in Local Universities and Colleges" [J]. Experimental Technology and Management, vol.36(2017), No.8, p.222-225(in Chinese).

[2] Tian Hai, Cui Gui-mei and Liu Hui-bo, et al: "Research and Practice on the Training Mode of Excellently Innovative Talents" [J]. Experimental Technology and Management, vol.36(2017), No.8, p.230-233(in Chinese).

[3] Zhang Li, Zuo Yu-sheng, Chen Jie, et al: "Development and Research of Preview System of College Physics Experiment in Independent Colleges" [J]. Experimental Technology and Management, vol.36(2017), No.7, p.203-206(in Chinese).

[4] Yan Wen-juan, He Guo-quan: "Exploration and practice on training mode of electronic information innovative application oriented talents" [J]. Experimental Technology and Management, vol.33(2016), No.6, p.21-24(in Chinese).

[5] Zhang Ling-yun, Dong Qiang: "Exploration and practice of applied talents training mode base on industry-university-research collaboration: a case study of Hefei University" [J]. Journal of Hefei University (Natural Sciences), vol.19(2014), No.4, p.70-73(in Chinese). 